\title{
Presenilin-1 Regulates Neural Progenitor Cell Differentiation in the Adult Brain
}

\author{
Archana Gadadhar, ${ }^{1}$ Robert Marr, ${ }^{2}$ and Orly Lazarov ${ }^{1}$ \\ ${ }^{1}$ Department of Anatomy and Cell Biology, College of Medicine, University of Illinois at Chicago, Chicago, Illinois 60612, and ${ }^{2}$ Department of Neuroscience, \\ Rosalind Franklin University of Medicine and Science, North Chicago, Illinois 60064
}

Presenilin-1 (PS1) is the catalytic core of the aspartyl protease $\gamma$-secretase. Previous genetic studies using germ-line deletion of PS1 and conditional knock-out mice demonstrated that PS1 plays an essential role in neuronal differentiation during neural development, but it remained unclear whether PS1 plays a similar role in neurogenesis in the adult brain. Here we show that neural progenitor cells infected with lentiviral vectors-expressing short interfering RNA (siRNA) for the exclusive knockdown of PS1 in the neurogenic microenvironments, exhibit a dramatic enhancement of cell differentiation. Infected cells differentiated into neurons, astrocytes and oligodendrocytes, suggesting that multipotentiality of neural progenitor cells is not affected by reduced levels of PS1. Neurosphere cultures treated with $\gamma$-secretase inhibitors exhibit a similar phenotype of enhanced cell differentiation, suggesting that PS1 function in neural progenitor cells is $\gamma$-secretase-dependent. Neurospheres infected with lentiviral vectors expressing siRNA for the targeting of PS1 differentiated even in the presence of the proliferation factors epidermal growth factor (EGF) and basic fibroblast growth factor (bFGF), suggesting that PS1 dominates EFG and bFGF signaling pathways. Reduction of PS1 expression in neural progenitor cells was accompanied by a decrease in EGF receptor and $\beta$-catenin expression level, suggesting that they are downstream essential transducers of PS1 signaling in adult neural progenitor cells. These findings suggest a physiological role for PS1 in adult neurogenesis, and a potential target for the manipulation of neural progenitor cell differentiation.

\section{Introduction}

Neural progenitor cells (NPCs) in the adult brain reside in discrete microenvironments, the subventricular zone (SVZ) and the subgranular layer (SGL) of the dentate gyrus (DG) (Kriegstein and Alvarez-Buylla, 2009; Aimone et al., 2010). These niches support NPC self-renewal, proliferation and differentiation into neurons and glia throughout life (Suh et al., 2009). However, the molecular basis for the transition of NPCs from proliferation to differentiation has remained largely elusive. Presenilin-1 (PS1) is the catalytic core of the aspartyl protease $\gamma$-secretase (De Strooper et al., 1998, 1999; Wolfe et al., 1999; Herreman et al., 2000; Li et al., 2000; Zhang et al., 2000) that catalyzes numerous molecules implicated in neurogenesis (for review, see WinesSamuelson and Shen, 2005; Lazarov and Marr, 2010). In humans, mutations in PS1 cause familial Alzheimer's disease (FAD) (Selkoe, 2001). Mice with targeted disruption in the PS1 locus showed impairments in neurogenesis. Beginning at embryonic day 14.5 the ventricular zone is substantially thinner, indicating a drastic reduction in the number of NPCs (Shen et al., 1997). In PS conditional double knock-out mice there is a severe depletion of NPCs characterized by their disrupted interkinetic nuclear mi-

\footnotetext{
Received Sept. 10, 2010; revised Nov. 19, 2010; accepted Dec. 23, 2010.

This study was supported by National Institutes of Health Grant AG033570 and an Alzheimer's Association Young Investigator Award (0.L.).

Correspondence should be addressed to Dr. Orly Lazarov, Assistant Professor, Anatomy and Cell Biology, College of Medicine, 808 South Wood Street, M/C 512, University of Illinois at Chicago, Chicago, IL 60612. E-mail: olazarov@uic.edu.

DOI:10.1523/JNEUROSCI.4767-10.2011

Copyright $\odot 2011$ the authors $\quad 0270-6474 / 11 / 312615-09 \$ 15.00 / 0$
}

gration (Kim and Shen, 2008). Reduced numbers of NPCs are thought to be due to premature differentiation, rather than a decrease in proliferation or cell death (Handler et al., 2000; Yang et al., 2000; Kim and Shen, 2008).

PS1 knock-out mice die in late embryogenesis, hampering the examination of the role of PS1 in regulation of adult neurogenesis. Information from transgenic mice harboring FAD-linked PS1 variants is controversial and inconclusive (Feng et al., 2001; Wang et al., 2004; Wen et al., 2004; Chevallier et al., 2005; Choi et al., 2008). In fact, this controversy is not surprising, as FADlinked PS1 transgenic mice generated so far offer little advantage when it comes to processes that take place in restricted areas of the postnatal brain with a unique population of NPCs, as transgenes are expressed in a ubiquitously, nonspecific manner, in large neuronal populations in the forebrain, making the relevance of these studies to adult neurogenesis highly questionable. Equally troubling is the neuropathology expressed in these mice, such as high levels of $\beta$-amyloid $42\left(\mathrm{~A} \beta_{42}\right)$, that may alter neurogenesis indirectly.

To establish a paradigm that examines PS1 function in the neurogenic niches of the adult brain exclusively we developed a lentiviral vector system that expresses small interfering RNAs (siRNAs) for the targeting of PS1, and a green fluorescent protein (GFP) marker for the tracking of targeted cells. Here we show that knocking down PS1 expression in NPCs in the adult brain decreases their proliferation and enhances their differentiation. NPCs expressing reduced levels of PS1 differentiate faster into neurons and glia than NPCs expressing endogenous levels of PS1. PS1 function in NPCs dominates the critical proliferation signals 
epidermal growth factor (EGF) and basic fibroblast growth factor (bFGF). Finally, PS1 regulates NPC differentiation in a $\gamma$-secretase-dependent manner and may exert its effect through EGF receptor (EGFR) and $\beta$-catenin signaling pathways. This study suggests a physiological role for PS1 in regulation of NPC differentiation in the adult brain.

\section{Materials and Methods}

Development of lentiviral vectors expressing siRNA for the targeting of PS1. The development of a lentiviral vector system to knockdown PS1 expression was designed to expresses siRNA sequences for targeting PS1, and to coexpress a GFP marker to track targeted cells. For this purpose, third generation (selfinactivating) lentiviral vectors were designed to express small-hairpin RNAs (shRNA) from the $3^{\prime}$ remnant U3 sequence as previously described (Brummelkamp et al., 2002; Tiscornia et al., 2006a). Two siRNA sequences targeting murine PS1 were chosen. One is based on a previously published sequence (5'AAGGCCCACTTCGTATGCTGG 3') (1.1) (Xie et al., 2004) and one by algorithm (S-fold, http:// sfold.wadsworth.org) (5'GGACCAACTTGCATTCCAT3'; 4.11) (Fig. 1A). As controls we generated vectors expressing irrelevant siRNAs: IR-8.1 (5'CTTCATTGTCGGCATGGGT $3^{\prime}$ ) and IR-9.1 (5'GTATAATACACCGCGCTAC3'). As an additional control, a lentiviral vector expressing GFP alone was used. For validation of shRNA constructs, N2a cells were transduced with the purified shRNA vector preparation followed by anti-PS1 immunoblot. Purification of viral stocks was done as previously described (Tiscornia et al., 2006b). Briefly, HEK-293T cells were transfected with the lentiviral vectors and packaging plasmids and lentiviral vectors concentrated/purified by centrifugation of cell culture supernatants.

Mouse lines. Adult male C57BL/6 mice used in these studies were purchased from the Jackson Laboratories (JAX Mice). Mice were used at 6-8 months of age for stereotaxic injections. C57BL/6 mice 2-4 months old were used for all in vitro neurosphere cultures.

Stereotaxic injection of lentiviral vectors expressing siRNA for PS1 targeting. Lentiviral vectors coexpressing either (1) GFP and siRNA for PS1 targeting (1.1 or 4.11) or (2) GFP and an irrelevant siRNA (IR 8.1 or 9.1) or (3) GFP alone, were stereotaxically injected $(n=80)$ unilaterally into the SGL of C57BL/6 mice ( $1 \mu \mathrm{l} / \mathrm{site} ; 0.25 \mu \mathrm{l} / \mathrm{min})$ using the following DG coordinates: (anteroposterior, $-3.0 \mathrm{~mm}$; mediolateral, $+2.0 \mathrm{~mm}$; dorsoventral, -2.5$)$. Mice were anesthetized using a mixture of ketamine and xylazine. The mice then had their heads shaved and wiped with $70 \%$ ethanol (EtOH). Animals were placed into the stereotaxic frame and a one-inch incision was made in the midline to reveal the bregma. The scalp was then cleared of tissue and wiped with $30 \%$ hydrogen peroxide to dehydrate the scalp. A small hole was drilled at the coordinate site as measured from the bregma according the mouse atlas of Paxinos and Franklin (2004). Animals then received unilateral injections of $1 \mu \mathrm{l}$ of lentivirus directly in the SGL. The virus was delivered using a $5 \mu \mathrm{l} \mathrm{Ham-}$ ilton syringe connected to a hydraulic system to inject the solution at a rate of $0.20 \mu \mathrm{l} / \mathrm{min}$. The injection needle was then left in place for another minute to ensure distribution of the lentivirus. The needle was slowly removed and the wounds were closed with sterile EZ-clips from Stoelt-
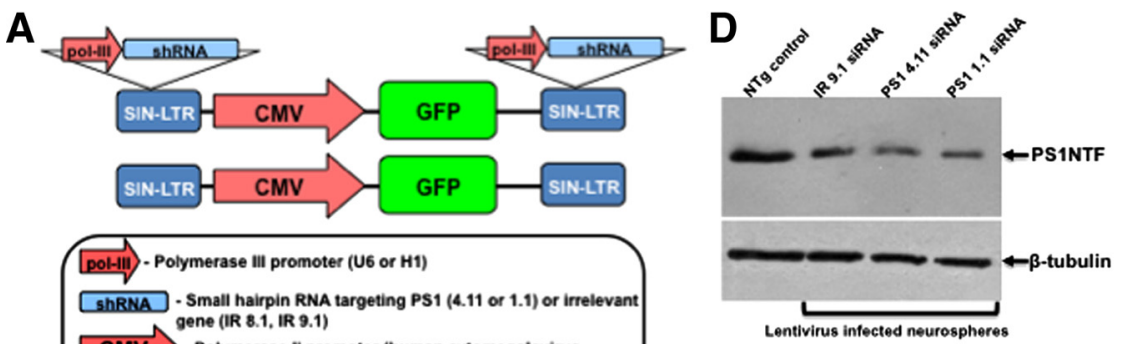

$\mathrm{E}$

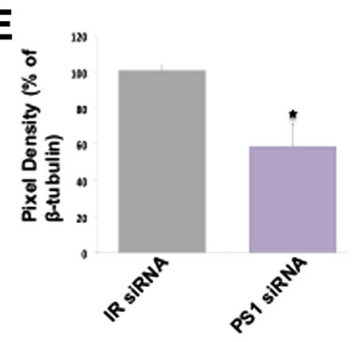

$\mathbf{F}$

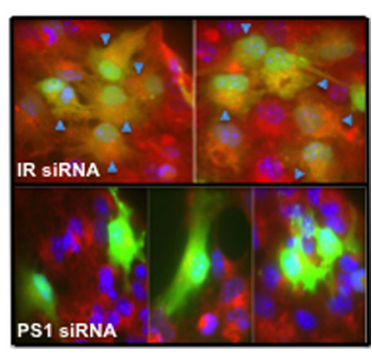

Figure 1. Reduced PS1 expression in adult neural progenitor cells following transduction with lentiviral vectors expressing siRn the targeting of PS1. A, Designs for lentiviral vectors used in this study. shRNA for the silencing of PS1 (PS1 1.1, PS1 4.11) or an irrelevant control shRNA (IR 8.1, IR 9.1) were inserted in the duplicated LTR regions. As an additional control GFP-Lenti was , Western blot analysis shows reduced expression of PS1 in N2a cells infected with lentiviral vectors expressing PS1 1.1, PS irrelevant control shRNA (IR 8.1, lane 3) or GFP-Lenti (lane 4) or noninfected N2a cells (lane 5). Lanes 6 and 7 serve as expression average reduction in PS1 expression in N2a cells infected with lentiviral vectors expressing PS1 1.1, PS1 4.11 shRNA for the targeting of PS1 $(n=3)$. D, Western blot analysis showing reduced expression of PS1 in neural progenitor cell cultures (neurospheres) following transduction with lentiviral vectors expressing PS11.1, PS1 4.11 shRNA for the targeting of PS1 compared with Densitometric analysis shows the average reduction in PS1 expression in neurospheres infected with lentiviral vectors expressing PS1 1.1, PS1 4.11 shRNA for the targeting of PS1 $(n=3) . F$, Immunostaining of neurospheres infected with lentiviral vectors using anti-PS1 antibodies shows reduced expression of PS1 in GFP + neurospheres infected with lentiviral vectors expressing PS1 1.1 or PS1 4.11 shRNA, compared with PS1 expression in GFP + neurospheres infected with lentiviral vectors expressing IR 8.1 or IR 9.1 (arrowheads point to GFP+PS1+ double-labeled cells; red, PS1; green, GFP; blue, DAPI).

ing. The mice were placed in cages individually and survived for 6 weeks after surgery.

$B r d U$ injections. Animals were given intraperitoneal injections of 100 $\mathrm{mg} / \mathrm{kg} 5^{\prime}$-bromo-2'deoxyuridine (BrdU) (Sigma) every $12 \mathrm{~h}$ for $3 \mathrm{~d}$. Animals were perfused $12 \mathrm{~h}$ after the last BrdU injection to study stem cell proliferation and differentiation. All animals were anesthetized with a mixture of ketamine and xylazine and transcardially perfused with 200 $\mathrm{ml}$ of cold $1 \times$ PBS followed by $100 \mathrm{ml}$ of $4 \%$ paraformaldehyde (PFA). The brains were then dissected and placed into $4 \%$ PFA for $24 \mathrm{~h}$ at $4^{\circ} \mathrm{C}$. They were then transferred into a solution of $30 \%$ sucrose and kept at $4^{\circ} \mathrm{C}$.

Neurosphere culture. SVZ derived neural stem cells were isolated as previously described (Demars et al., 2010). Briefly, SVZ of 2- to 4-month-old C57BL/6 mice were dissected and chopped. The tissue was incubated in a mixture of activated papain (Sigma), EDTA (Sigma), and L-cysteine (Sigma), and $0.1 \%$ DNase for $40 \mathrm{~min}$ at $37^{\circ} \mathrm{C}$. Tissue was then disassociated and centrifuged at $1000 \times g$ for $5 \mathrm{~min}$. Cells were then plated in complete medium [(water, DMEM-F-12; Invitrogen), glucose (Sigma), $\mathrm{NaHCO}_{3}$ (Sigma), HEPES (Sigma), L-glutamine (Invitrogen), penicillin/streptomycin (Invitrogen), putrescine (Sigma), apo- 
transferrin (Sigma), insulin (Roche), selenium (Sigma), progesterone (Sigma), BSA (Sigma), heparin (Sigma), EGF (20 ng/ml; Peprotech), bFGF (10 ng/ml; Peprotech)] and incubated in $37^{\circ} \mathrm{C}, 5 \% \mathrm{CO}_{2}$ for $10 \mathrm{~d}$. Cells were passaged two to three times to clear debris before using in experiments.

L-685,458, DAPT $\gamma$-secretase inhibitors. Neurosphere cultures were treated with the $\boldsymbol{\gamma}$-secretase inhibitor $\mathrm{N}$-[N-(3,5-difluorophenacetyl)-Lalanyl]-(S)-phenylglycine tert-butyl ester (DAPT) $(0.5 \mu \mathrm{M}$, Calbiochem) or with the transition state analog inhibitor L-685,458 [(5S)-(tertbutoxycarbonylamino)-6-phenyl-( $4 R$ )-hydroxy-( $2 R)$-benzylhexanoyl)-Lleucy-L-phenylalaninamide] (10 $\mu \mathrm{M}$, Sigma) for $48 \mathrm{~h}$.

Antibodies. The following primary antibodies were used in this study: Rat anti-BrdU polyclonal (1:500), GFP marker mouse anti-GFP monoclonal (1:200; Santa Cruz Biotechnology), chicken anti-TUJ-1 polyclonal (1:100 Millipore Bioscience Research Reagents), mouse anti-TUJ-1 monoclonal (1:5000; Promega) early neuronal marker goat antidoublecortin polyclonal (DCX) (1:400; Santa Cruz Biotechnology), rabbit anti-PS1NTF polyclonal (1:5000, a generous gift from Dr. Gopal Thinakaran, University of Chicago, Chicago, IL), glial marker rabbit anti-glial fibrillary acidic protein polyclonal (GFAP) (1:400 Dako), glial marker GFAP (1:500 Millipore), mouse anti-NeuN monoclonal (1:400; Millipore Bioscience Research Reagents), mouse anti-actin monoclonal (1:5000; Millipore Bioscience Research Reagents), neural stem cell marker mouse anti-nestin monoclonal (1:200; Millipore Bioscience Research Reagents). The following secondary antibodies were used from Jackson ImmunoResearch Laboratories: Cy3-conjugated donkey antirat (1:500), biotin-conjugated donkey anti-mouse (1:250), Cy2conjugated streptavidin (1:250), Cy5-conjugated donkey anti-chicken (1:250), Cy5-conjugated donkey anti-mouse (1:250), Cy3-conjugated donkey anti-mouse (1:500), Cy5-conjugated donkey anti-goat (1:250), Cy3-conjugated donkey anti-rabbit (1:500), Cy5-conjugated donkey anti-rabbit (1:250). Alexa 488 goat anti-mouse IgM (1:400; Invitrogen), peroxidase-conjugated rabbit anti-mouse (1:5000; Pierce Biotechnology), protein A-peroxidase (1:1000; Sigma), and 4',6-diamidino-2phenylindole dihydrochloride (DAPI) nucleic acid stain (1:50,000; Invitrogen) were also used.

$B r d U$ proliferation assay. Neural progenitor cells were plated at a density of $1.5 \times 10^{4}$ cells/well into a round-bottom 96-well plate in complete medium. Cells are incubated for $24 \mathrm{~h}$ at $37^{\circ} \mathrm{C}, 5 \% \mathrm{CO}_{2}$. A $5 \mu \mathrm{M} \mathrm{BrdU}$ solution was added to each well and incubate at $37^{\circ} \mathrm{C}, 5 \% \mathrm{CO}_{2}$ for $48 \mathrm{~h}$. Plates were spun down at $1000 \times g$ for 10 min to pellet the cells. The cells were fixed with $70 \% \mathrm{EtOH}$ and $0.1 \mathrm{~N} \mathrm{NaOH}$ for $30 \mathrm{~min}$ at room temperature. Cells were incubated in mAb BrdU (1:300, Novocastra) primary antibody for $1 \mathrm{~h}$. After washing, cells were incubated in secondary antibody rabbit anti-mouse HRP (1:5000, Pierce) for $30 \mathrm{~min}$. The cells were then washed and incubated with tetramethylbenzidine (TMB) substrate solution (Invitrogen) for $15 \mathrm{~min}$ in the dark. To stop the reaction, a solution of $2.5 \mathrm{~N}$ sulfuric acid was added to the cells with TMB. The plates were read using a spectrophotometric microtiter plate reader set at a dual wavelength of $450-595$. Each experimental group includes 4 replicates $(n=10)$

Clonogenic assay. Lentiviral infected or $\gamma$-secretase inhibitor-treated neurospheres were singly disassociated and plated at a density of 2500 cells/ $\mathrm{ml}$ onto a $2 \mathrm{~cm}$ grid plate. Neurospheres were counted after $7 \mathrm{~d}$ using an upright microscope. $n=5$ for each experimental group.

Neurosphere differentiation assay. For differentiation assays, neurospheres or single cells were plated onto glass coverslips coated with Matrigel (BD Biosciences) in complete media without EGF and bFGF and with the addition of $5 \%$ fetal bovine serum. Cells were allowed to differentiate for various time points at $37^{\circ} \mathrm{C}, 5 \% \mathrm{CO}_{2}$. The cells were then fixed with $4 \%$ PFA for $30 \mathrm{~min}$ and immunostained. $n=5$ for each experimental group.

Immunohistochemistry. Brains were sectioned sagittally at $50 \mu \mathrm{m}$ using a microtome (Leica) and placed into cryoprotectant (glycerol, ethylene glycol, PBS). Every sixth section was used for immunohistochemistry. To expose the BrdU antigen, sections were pretreated with deionized formamide and SSC for $2 \mathrm{~h}$ at $65^{\circ}$ in a shaking water bath. Sections were then rinsed with SSC and incubated in a $2 \mathrm{~N} \mathrm{HCl}$ solution for $30 \mathrm{~min}$ at $37^{\circ} \mathrm{C}$. Sections were then neutralized with $0.1 \mathrm{~m}$ borate buffer for $10 \mathrm{~min}$. Sec- tions were blocked for $1-3 \mathrm{~h}$ in TBS, normal donkey serum, and Triton $\mathrm{X}-100\left(\mathrm{TBS}^{++}\right)$before being incubated in primary antibodies in TBS and Triton X-100 $\left(\mathrm{TBS}^{+}\right.$) for $72 \mathrm{~h}$ at $4^{\circ} \mathrm{C}$. Sections were blocked again in TBS $^{++}$before being incubated in secondary antibodies for $2 \mathrm{~h}$ at room temperature. Sections were then mounted onto glass coverslips using polyvinyl acetate-1,4-diazabicyclo-[2.2.2] octane (PVA-DABCO). Immunohistochemistry was followed by stereological analysis.

Cell culture immunostaining. Differentiated cells were fixed using $4 \%$ PFA for $30 \mathrm{~min}$ at room temperature. Cells were washed three times in TBS and blocked in $\mathrm{TBS}^{++}$for $1 \mathrm{~h}$. Cells were then incubated in primary antibodies for $2 \mathrm{~h}^{\text {in } \mathrm{TBS}^{+}}{ }^{+}$. Following a second block in $\mathrm{TBS}^{++}$for 30 min, cells were incubated in secondary antibodies in $\mathrm{TBS}^{+}$for $1 \mathrm{~h}$ at room temperature. Cells were incubated in a DAPI solution for $5 \mathrm{~min}$. Cells were then washed and mounted using PVA-DABCO.

Stereological analysis. Quantification of immunostained sections were done using Stereo Investigator (MicroBrightField Bioscience). Immunostained sections were counted using the following parameters: the counting frame was set to $115 \mu \mathrm{M} \times 115 \mu \mathrm{M}$, and sampling grid was set at 122 $\mu \mathrm{M} \times 122 \mu \mathrm{M}$. The section thickness was averaged at $35 \mu \mathrm{M}$. The entire dentate gyrus was counted due to the scarcity of BrdU+ cells.

Western blot analysis. Protein extraction of tissue was prepared using a $1 \times$ TNE buffer [50 mm Tris, $150 \mathrm{~mm} \mathrm{NaCl,} 5$ mm EDTA, 0.5\% SDS, 100 mm PMSF, and Protease Inhibitor Cocktail (Sigma)]. Protein extraction of in vitro cells was prepared using a $1 \times$ immunoprecipitation buffer ( $150 \mathrm{~mm} \mathrm{NaCl}, 50 \mathrm{~mm}$ Tris-Cl, $0.5 \%$ Triton X-100, 0.5\% sodium deoxycholate, 5 mm EDTA, 0.25\% SDS, 100 mm PMSF, and Protease Inhibitor Cocktail), or $50 \mathrm{~mm}$ HEPES and 1\% SDS lysis buffer. Protein was extracted by homogenization of tissue in the appropriate lysis buffer. Protein concentration was determined using the BCA (bicinchoninic acid) method (Pierce). Equal amounts of protein were taken for immunoblotting.

Real time reverse transcriptase $P C R$. Total RNA was extracted using TRI Reagent (Sigma). Two micrograms of total RNA was treated with DNase for $1 \mathrm{~h}$ (RNase free, Ambion) and then reverse transcribed into cDNA using a mix of oligodT and random primers (High-Capacity cDNA Reverse Transcription Kit, Applied Biosystems). Primer sets were CycloA-5' GGC CGA TGA CGA GCC C, CycloA-3' TGT CTT TGG AAC TTT GTC TGC AA at, Egfr $5^{\prime}$ ATCCTCTGCAGGCTCAGAAA, Egfr 3' GGCGTTGGAGGAAAAGAAAG, Bmil-5' AGCAGCAATGACTGTGATGCACTTGAG, Bmil-3' GCTCTCCAGCATTCGTCAGTCCATCCC, Catnb-5' CAGCTTGAGTAGCCATTGTCC, Catnb-3' GAGCCGTCAGTGCAGGAG, Tlx1-5' TCACGTTCCTCTGCTGTCTG, Tlx1-3' CAAGGCGCTCAAAATGACC. DCX-5' TTCAGGACCACAAGCAATGA, DCX-3' GGAAACCGGAGTTGTCAAAA, $\beta$-III tubulin-5' ATGCTTGGGACTACGTTTGG, $\beta$-III tubulin-3' TGAGGCCTCCTCTCACAAGT, GFAP-5' CACGAAGCTAACGACTATCGC, GFAP-3' CTCTAGGGACTCGTTCGTGC, PDGF-5' CTGCACCAAGTCAGGTCCC, PDGF-3' CTTCTCTGGGTGTTGGCTCA, Nestin-5' GGTCACTGT CGCCGCTACTC, Nestin-3' CGGACGTGGAGCACTAGAGAA. Quantitative real-time (RT)-PCR was performed with SYBRGreen PCR Master Mix (Applied Biosystems) using an ABI Prism 7700 sequence detection system. The results were analyzed using the comparative $\Delta \Delta C_{\mathrm{t}}$ method (normalized to the amplification cycle counts of the cyclophilin reference gene). Unpaired $t$ test and ANOVA used for statistical analysis.

\section{Results}

Targeting PS1 in NPCs and in neurogenic niches exclusively

To examine the role of PS1 in regulation of NPCs and their progeny in the adult brain we developed lentiviral vectors expressing siRNA for the targeting of PS1 (Fig. 1A). Viral vectors coexpress GFP for the identification of infected cells and their progeny. To rule out off-target effects of the siRNA, we developed 2 shRNA for the targeting of PS1 (designated 1.1 and 4.11 PS1 siRNA) and 2 control shRNA expressing irrelevant sequences (IR 8.1, 9.1 siRNA). As an additional control we infected neurospheres in vitro and in vivo with lentiviral vectors expressing GFP only (GFP-Lenti, Fig. 1A). To validate that infection of cells with lentiviral vectors expressing siRNA for the targeting of PS1 results in 
a reduction of PS1 expression, we first infected murine neuroblastoma N2a cells with the five lentiviral vector preparations. As expected, infection of N2a cells with both lentiviral vectors expressing siRNA for the targeting of PS1 induced a reduction in PS1 expression (Fig. 1B,C). Likewise, infection of neurosphere culture revealed a reduction in PS1 expression in cultures infected with lentiviral vectors expressing PS1 1.1 and PS1 4.11 siRNA, but not in cultures infected with lentiviral vectors expressing IR 8.1, IR 9.1 siRNA compared with noninfected neurospheres (Fig. 1D,E). To confirm a reduction in PS1 expression in neurospheres cultures infected with lentiviral vectors expressing PS1 1.1 and PS1 4.11 siRNA, neurospheres were immunostained with anti-PS1 antibodies $5 \mathrm{~d}$ after lentiviral infection. PS1 immunoreactivity was significantly reduced in GFP+ neurospheres infected with lentiviral vectors expressing PS1 1.1 and PS1 4.11 siRNA, compared with GFP+ neurospheres expressing IR 8.1, IR 9.1 siRNA (Fig. $1 F)$. We then injected lentiviral vectors into the SGL and the SVZ of adult mice stereotaxically (Fig. 2). Examination of PS1 expression in protein extracts of SGL $(n=16$; Fig. $2 A, B$ ) and SVZ (data not shown) of mice infected with lentiviral vectors expressing PS1 1.1 and PS1 4.11 siRNA revealed a decrease in PS1 expression compared with SGL and SVZ of mice infected with lentiviral vectors expressing IR 8.1, IR 9.1 siRNA or GFP-Lenti (Fig. $2 A, B$ ). To verify specificity of infection in the neurogenic microenvironments, brain sections of mice infected with lentiviral vectors were subject to immunohistochemical analysis (Fig. 2C). Six weeks after stereotaxic injection of lentiviral vectors, GFP+ cells were confined to the SGL with some GFP+ cells in the granule layer of the dentate gyrus. No GFP+ cells could be detected in any other area of the hippocampus or in any other brain area (Fig. $2 C a-C d$; supplemental Fig. 1, available at www.jneurosci.org as supplemental material). Likewise, injection of lentiviral vectors into the SVZ resulted in massive GFP+ expression of progenitor cells (Fig. 2Ce). These results suggest that lentiviral vectors expressing siRNA for PS1 targeting, successfully downregulate PS1 expression in the neurogenic microenvironments and in neurosphere cultures derived from these niches.

Targeting PS1 in the SGL of the dentate gyrus reduces the number of rapidly proliferating NPCs and increases the number of differentiating cells

To examine the effect of reduced PS1 expression on neurogenesis, lentiviral vectors expressing PS1 1.1, PS1 4.11, IR 8.1, IR 9.1 siRNA or GFP-Lenti were injected into the SGL. Six weeks later
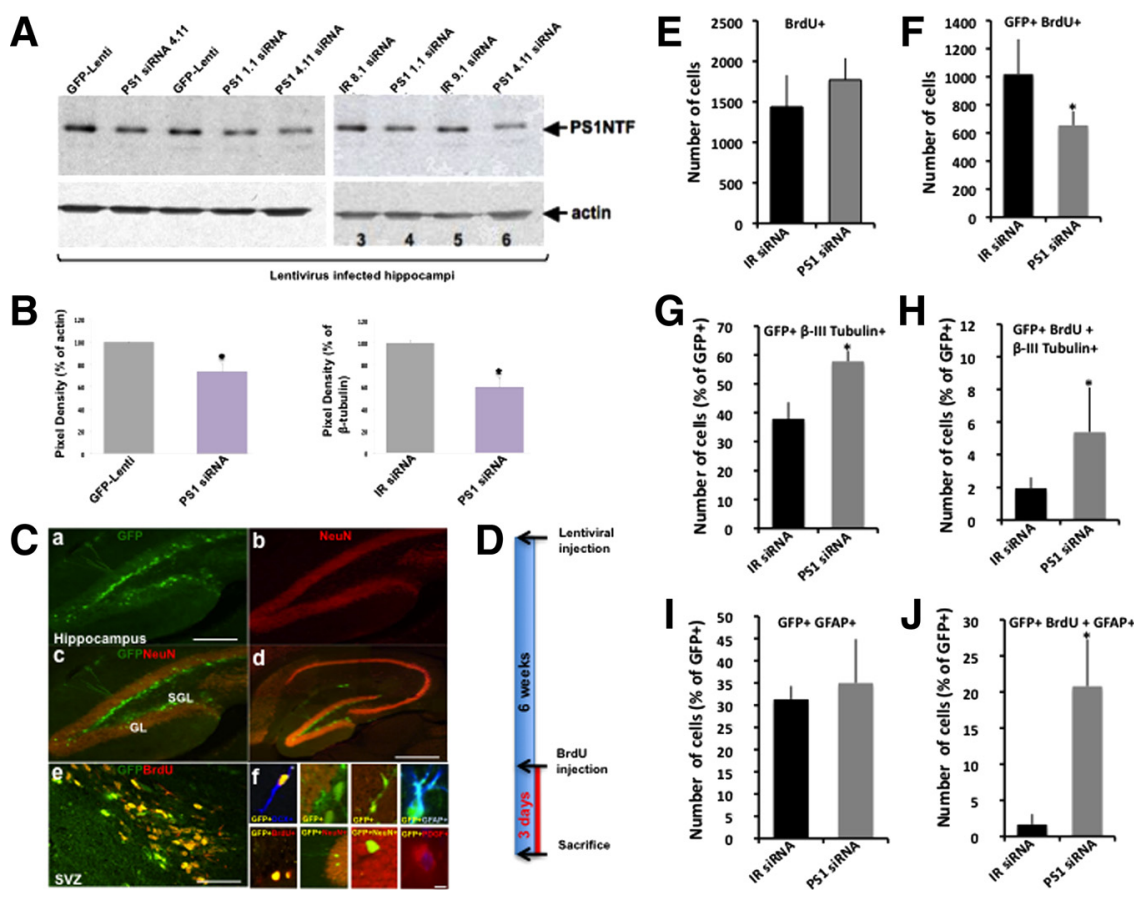

Figure 2. Downregulation of PS1 expression in NPCs in the SGL of adult mice enhances their differentiation into neurons and glia. $\boldsymbol{A}$, Reduced PS1 expression in protein extracts of mouse hippocampi infected with lentiviral vectors expressing PS1 1.1, PS1 4.11 shRNA for the targeting of PS1, compared with hippocampi infected with lentiviral vectors expressing control IR 8.1, IR 9.1 shRNA or GFP-Lenti. $\boldsymbol{B}$, Densitometric analysis shows the average reduction in PS1 expression in hippocampi infected with lentiviral vectors expressing PS1 1.1, PS1 4.11 shRNA for the targeting of PS1 compared with hippocampi infected with GFP-Lenti or IR shRNA $(n=3)$. C, Confocal images of brain sections of 6 -month-old C57BL/ 6 mice 6 weeks after stereotaxic injection of lentiviral vectors expressing GFP and PS1 siRNA into the SGL $(\mathbf{C a}-\mathbf{C d})$ or into the SVZ (Ce). Ca, A mass of GFP + cells in the SGL of the dentate gyrus. GFP + cells are present mainly in the SGL. Some GFP + cells can be detected in the granule layer (GL). $\boldsymbol{C b}, \mathrm{NeuN}+$ immunolabeled neurons in the DG. C, d, Merged images of NeuN + immunolabeling and GFP + staining in the DG (Cc) and in whole hippocampus $(\boldsymbol{C d})$ reveals that GFP + cells in the SGL are NeuN negative and in turn NeuN + cells in other hippocampal areas are GFP negative. Ce, Confocal image of GFP + cells (green) immunolabeled with antibodies raised against BrdU (red), as detected in the SVZ of mice injected with lentiviral vectors 6 weeks after injection. Note that the vast majority of cells are GFP + BrdU + double labeled. Scale bar, $150 \mu \mathrm{m}(\mathbf{C a}-\mathbf{C c}), 250 \mu \mathrm{m}(\mathbf{C d})$ and $75 \mu \mathrm{m}(\mathbf{C e})$. (ff, GFP + neural progenitor cells express a variety of progenitor and lineage-specific markers detected by confocal analysis. Top from left: GFP +DCX+ cell; GFP + cells at the SGL are NeuN (red) negative; GFP + BrdU + cells at the SGL extend processes toward the granular layer of the DG; GFP + GFAP + ; bottom from left: GFP + BrdU + cell in the granule layer; GFP + NeuN + cell (NeuN red) in the granular layer of the dentate gyrus; GFP + cells that migrated to the granule cell layer of the DG and extend processes toward the molecular cell layer of the dentate gyrus; PDGFR + BrdU + GFP + cell. Scale bar, $50 \mu \mathrm{m}$. D, A diagram showing the experimental procedures of in vivo experiments. $\boldsymbol{E}, \boldsymbol{F}$, Analysis of cell proliferation in the DG of adult mice injected with lentiviral vectors shows that the number of total proliferating $(\mathrm{BrdU}+)$ cells in the SGL is comparable in the brains of animals injected with lentiviral vectors expressing PS1 1.1, PS1 4.11 IR 8.1, IR 9.1 shRNA $(\boldsymbol{E})$. However, the number of GFP + BrdU + is significantly lower in the brains of mice injected with lentiviral vectors expressing PS1 1.1, PS1 4.11, compared with number in the brains of mice injected with lentiviral vectors expressing IR 8.1, IR 9.1 or GFP-Lenti control $(\boldsymbol{F})$, suggesting that downregulation of PS1 in target NPCs decreased their proliferation. $\boldsymbol{G}$, An increased number of neurons (GFP $+\beta$-III tubulin + ) in the brains of mice injected with lentiviral vectors expressing PS1 1.1, PS1 4.11, compared with number in the brains of mice injected with lentiviral vectors expressing IR 8.1, IR 9.1 or GFP-Lenti control. $\boldsymbol{H}$, An increase in the number of new neurons in the brains of mice injected with lentiviral vectors expressing PS1 1.1, PS1 4.11, compared with number in the brains of mice injected with lentiviral vectors expressing IR 8.1, IR 9.1 or GFP-Lenti control. $t$ test ${ }^{*} p<0.05$. I, A slight increase in the number of GFP + GFAP + cells in the brains of mice injected with lentiviral vectors expressing PS1 1.1, PS1 4.11.J, A significant increase in the number of newly formed astrocytes (GFP + BrdU + GFAP +) in the brains of mice injected with lentiviral vectors expressing PS1 1.1, PS1 4.11, compared with number in the brains of mice injected with lentiviral vectors expressing IR 8.1, IR 9.1 or GFP-Lenti control. 
A
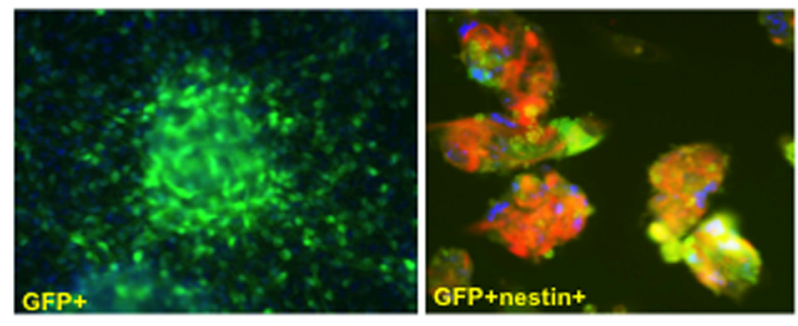

B

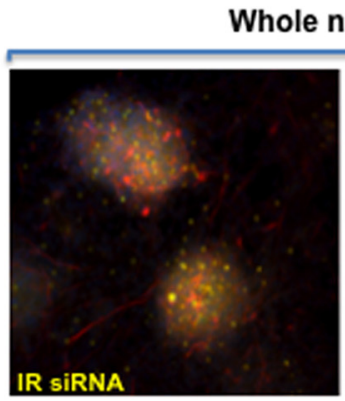

C

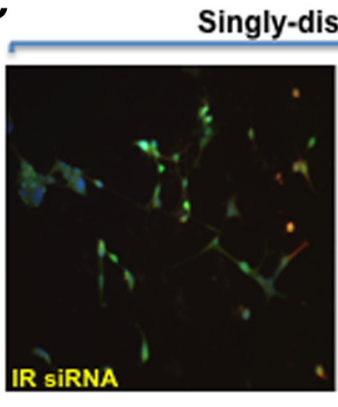

E
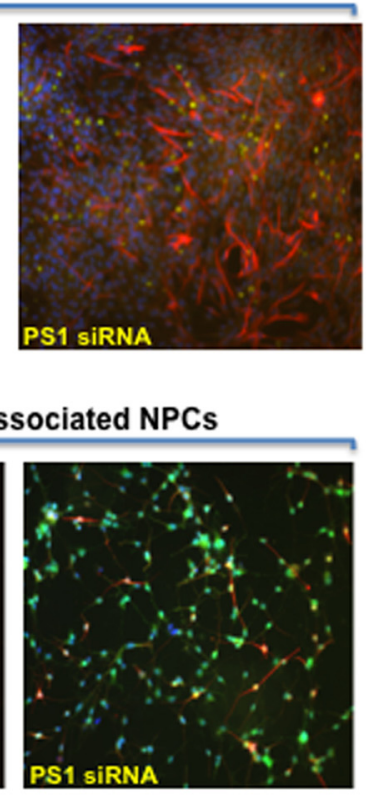
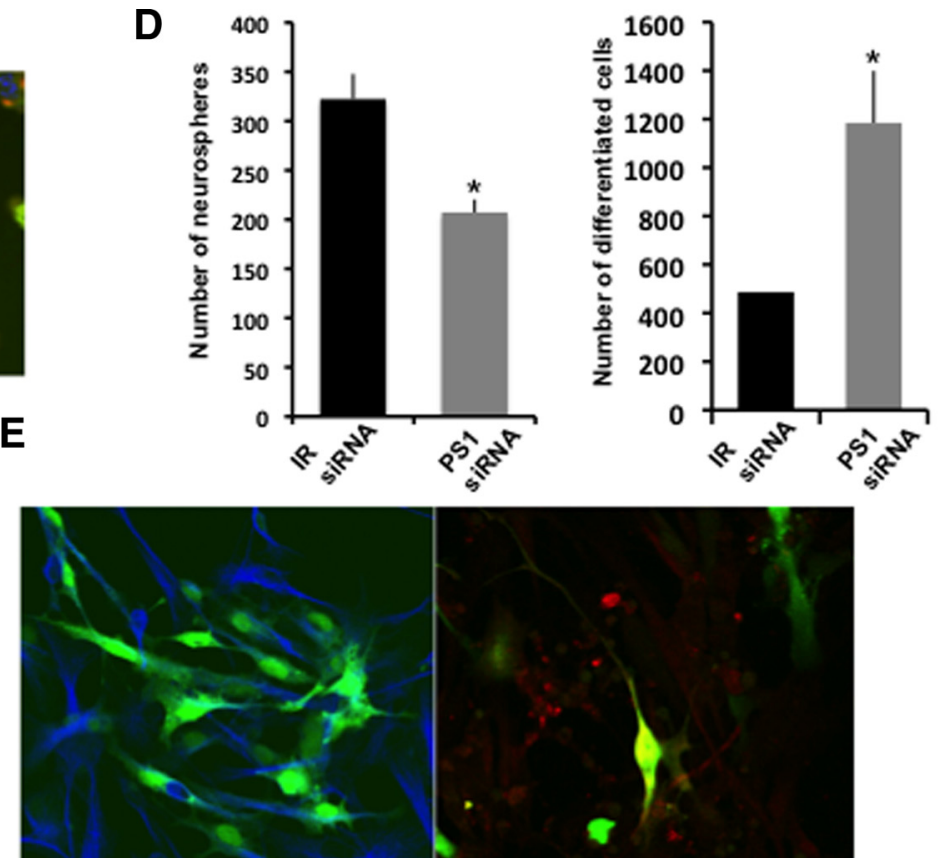

GFP+ $\beta$-tubulin+
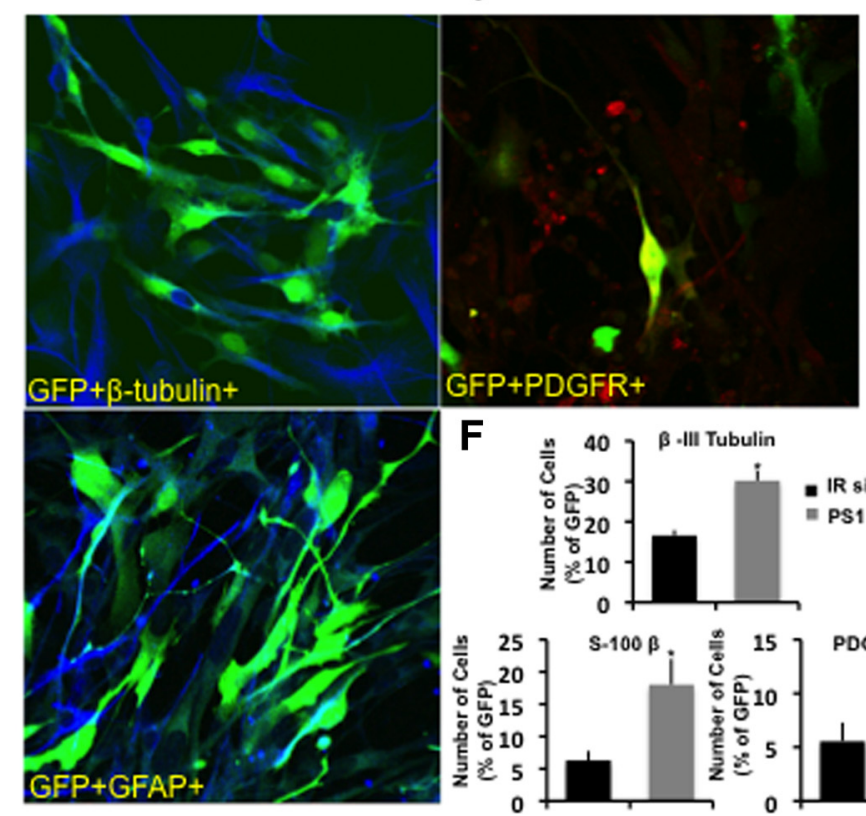

0

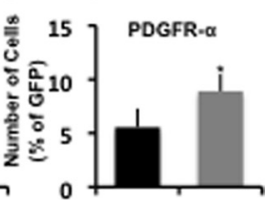

Figure 3. Downregulation of PS1 in neurosphere cultures enhances their differentiation without affecting multipotentiality. $A$, Neurosphere culture transduced with lentiviral vectors expressing PS1 1.1, PS1 4.11, IR 8.1, IR 9.1 express GFP (left and right panel), as well as the neural progenitor cell marker nestin (right panel; orange; nestin + GFP+; blue, DAPI). $\boldsymbol{B}$, Neurospheres transduced with lentiviral vectors expressing PS1 1.1, PS1 4.11 for PS1 targeting readily differentiate, while neurospheres transduced with lentiviral vectors expressing IR 8.1 or IR 9.1, or GFP-Lenti control maintain sphere morphology (green, GFP; red, $\beta$-tubulin; blue, DAPI). C, Singly dissociated neural progenitor cells transduced with lentiviral vectors expressing PS1 1.1, PS1 4.11 for PS1 targeting exhibit enhanced differentiation compared with progenitors transduced with lentiviral vectors expressing IR 8.1 or IR 9.1 control (green, GFP; red, $\beta$-tubulin; blue, DAPI). D, Number of neurospheres (left panel) generated from neural progenitor cells infected with lentiviral vectors expressing PS1 1.1, PS1 4.11, is significantly reduced, while the number of differentiated cells is increased (right panel) compared with neural progenitor cells infected with lentiviral vectors expressing IR 8.1, IR 9.1 siRNA, or GFP-Lenti. E, Neural progenitor cells infected with lentiviral vectors expressing PS1 1.1, PS1 4.11 can give rise to neurons (GFP $+\beta$-tubulin + ), astrocytes (GFP + GFAP + ) and oligodendrocytes (GFP + PDGFR + ), suggesting that downregulation of PS1 does not affect their multipotentiality. $\boldsymbol{F}$, Neural progenitor cells infected with lentiviral vectors expressing PS1 1.1, PS1 4.11 give rise to increased number of differentiated cells of all three lineages, neurons, astrocytes and oligodendrocytes. $t$ test ${ }^{*} p<0.05$.

PS1 1.1, PS1 4.11 (Fig. 2F), suggesting that downregulation of PS1 expression decreased NPC proliferation in the SGL of these mice. To examine whether reduction in rate of proliferation in cells expressing siRNA for PS1 targeting is accompanied by alterations in extent of differentiation, brain sections were coimmunolabeled with neuronal and glial lineage markers (Fig. 2Cf). The number of infected neurons (GFP $+\beta$-tubulin + ) and astrocytes $(\mathrm{GFP}+\mathrm{GFAP}+)$ was quantified by stereological analysis. The results show a significant increase in the number of neurons $(\mathrm{GFP}+\beta$-tubulin +$)$ in the SGL of mice injected with lentiviral vectors expressing siRNA for PS1 targeting (Fig. 2G). In addition we observed an increase in the number of neuroblasts $(\mathrm{GFP}+\mathrm{BrdU}+\beta$-tubulin +$)$ in the SGL of mice injected with lentiviral vectors expressing siRNA for PS1 targeting (Fig. $2 \mathrm{H}$ ), suggesting that reduced expression of PS1 enhances neuronal differentiation in the SGL. Examination of the number of infected astrocytes revealed a slight but insignificant increase in the number of astro- cytes (GFP+GFAP+, Fig. 2I), but a dramatic increase in the number of newly formed astrocytes (GFP+BrdU + GFAP+; Fig. $2 J)$ in the SGL of mice injected with lentiviral vectors expressing siRNA for PS1 targeting. Together, these results suggest that downregulation of PS1 in NPCs in the SGL of adult mice enhances neuronal differentiation and increases the number of astrocytes, and this increase is accompanied by a decrease in the number of rapidly proliferating NPCs.

\section{Downregulation of PS1 expression enhances NPC}

differentiation into neurons and glia

To determine whether downregulation of PS1 expression in NPCs enhances their differentiation, neurosphere cultures were infected with lentiviral vectors expressing PS1 1.1 or PS1 4.11 siRNA, or with lentiviral vectors expressing IR 8.1, IR 9.1 siRNA, or with GFP-Lenti (Fig. 3A). To induce cell differentiation, infected neurospheres were then cultured on Matrigel for $24 \mathrm{~h}$. 
A

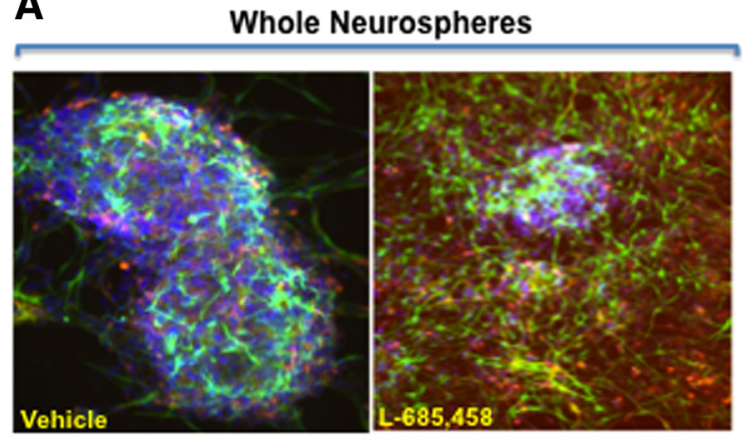

B

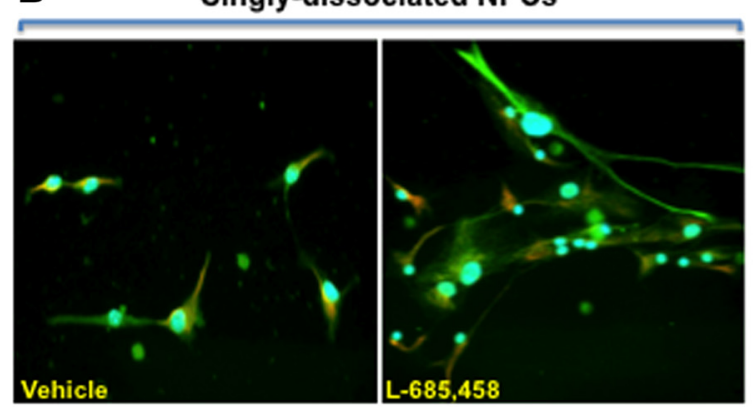

C

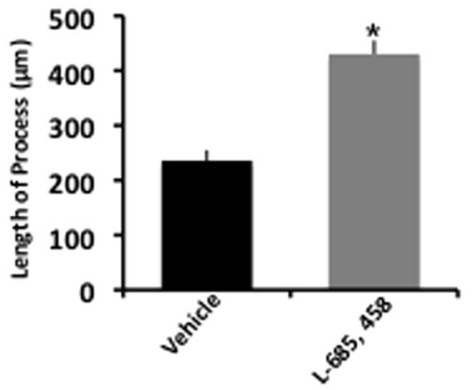

D
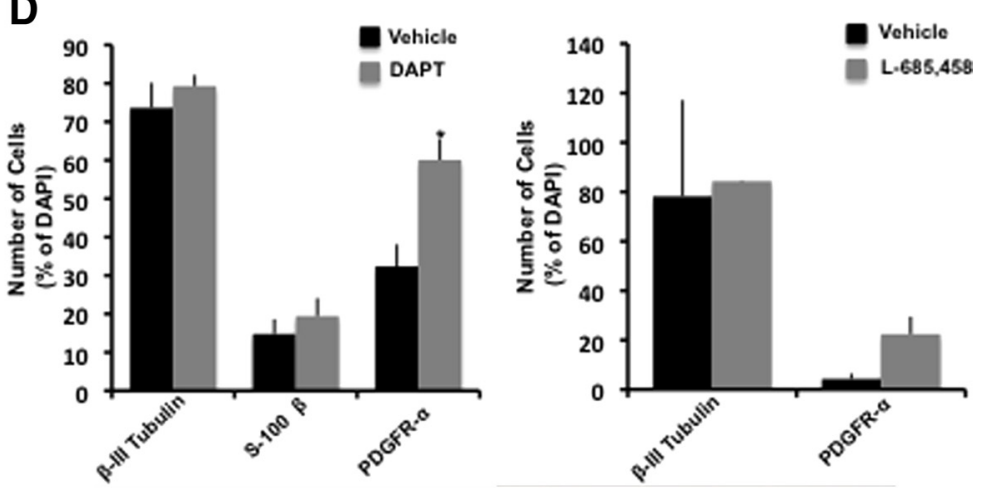

E
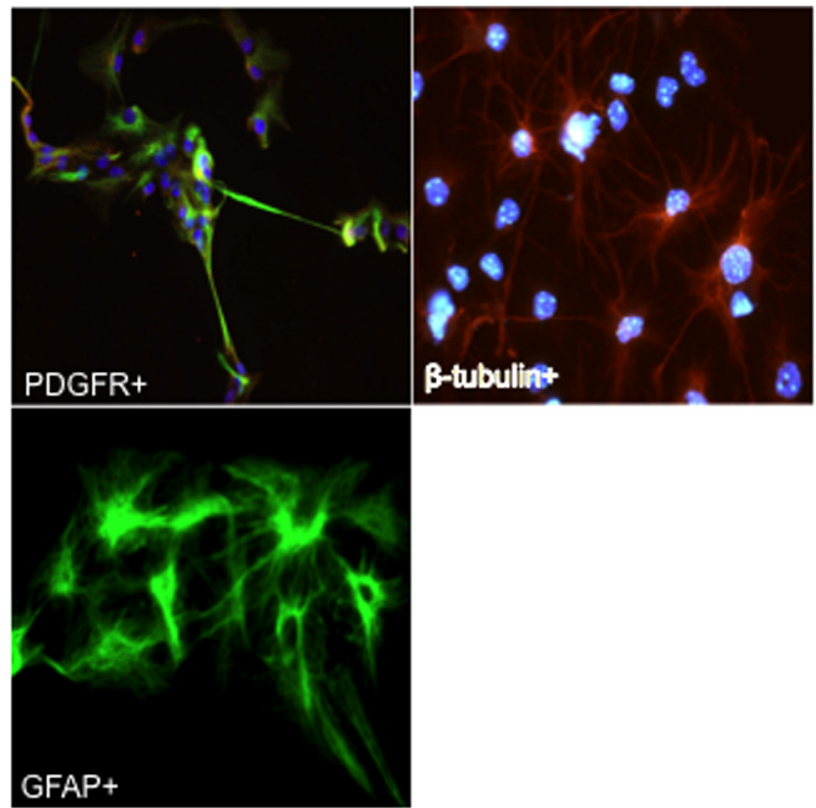

Figure 4. PS1 effect on neural progenitor cells is $\gamma$-secretase-dependent. $\boldsymbol{A}, \boldsymbol{B}$, Neural progenitor cells treated with the $\gamma$-secretase inhibitor $\mathrm{L}$-685,458, either as neurospheres $(\boldsymbol{A})$ or as singly dissociated cells $(\boldsymbol{B})$ differentiate faster than progenitors treated with vehicle (green, GFAP; red, $\beta$-tubulin; blue, DAPI). $C$, Quantification of the length of cell processes reveals significantly more processes in neural progenitor cells treated with L-685,458 compared with vehicle. $\boldsymbol{D}$, Quantitative analysis of cell lineage reveals a slight increase in the number of new neurons and astrocytes in cells treated with L-685,458 or DAPT and a significant increase in the number of new oligodendrocytes. $\boldsymbol{E}$, Neural progenitor cells treated with L-685,458 or DAPT differentiate into $\beta$-tubulin + neurons, $\mathrm{S} 100 \beta+$ astrocytes and PDGFR + oligodendrocytes. $t$ test ${ }^{*} p<0.05$.

Neurospheres infected with lentiviral vectors expressing IR 8.1, IR 9.1 siRNA, or with GFP-Lenti exhibited round sphere-like morphology (Fig. 3B). In contrast, neurospheres infected with lentiviral vectors expressing PS1 1.1 or PS1 4.11 siRNA lost the sphere morphology; cells migrated out and differentiated into process-bearing cells (Fig. 3B). NPCs infected with lentiviral vectors expressing PS1 1.1 or PS1 4.11 siRNA differentiated faster than NPCs infected with lentiviral vectors expressing IR 8.1, IR 9.1 siRNA, or with GFP-Lenti even when cultured as single-cells (Fig. 3C). To quantify extent of cell differentiation following PS1 downregulation, neurospheres infected with lentiviral vectors expressing PS1 1.1, PS1 4.11, IR 8.1, IR 9.1 siRNA, or GFP-Lenti were singly dissociated and an equal number of single cells were cultured for each infected group. Seven days later, the number of neurospheres in cultures infected with PS1 siRNA was significantly lower compared with the number of neurospheres in cultures infected with IR siRNA (Fig. 3D). In contrast, the number of differentiated cells was significantly higher in cultures infected with PS1 siRNA compared with cultures infected with IR siRNA (Fig. 3D). It should be noted that neurospheres differentiated in cultures infected with PS1 siRNA despite the presence of the po- tent proliferation factors bFGF and EGF, suggesting that PS1 dominates the proliferative effect of these growth factors. To examine whether reduced PS1 levels in NPCs affect multipotentiality, differentiating NPCs infected with lentiviral vectors expressing PS1 or IR siRNA were immunostained for cell-lineage markers. GFP + NPCs could differentiate into neurons, astrocytes and oligodendrocytes independently of PS1 expressing levels (Fig. 3E). Quantification of the number of differentiated neurons, astrocytes and oligodendrocytes revealed an increase in all three lineages in cultures infected with lentiviral vectors expressing PS1 siRNA (Fig. $3 F$ ), suggesting that reduced levels of PS1 do not alter multipotentiality.

\section{Regulation of NPC differentiation by PS1 is $\gamma$-secretase dependent}

To determine whether enhancement of NPC differentiation following PS1 downregulation is $\gamma$-secretase-dependent, neurospheres were treated with the $\boldsymbol{\gamma}$-secretase inhibitor DAPT or with the transition state analog inhibitor L-685,458 or with vehicle, and cultured on Matrigel. Twenty-four hours later, neurospheres treated with vehicle exhibited sphere morphology with some ini- 
tial processes indicating cell differentiation (Fig. $4 A$ ). In contrast, and similar to neurospheres infected with PS1 siRNA, neurospheres treated with either DAPT or L-685,458 lost sphere morphology. Cells migrated out of the neurosphere, and differentiated (Fig. 4A). Similarly, singly dissociated NPCs treated with either DAPT or L-685,458 differentiated faster than NPCs treated with vehicle (Fig. 4B). Quantification of the length of cell processes revealed a dramatic increase in process length in L-685,458-treated NPCs (Fig. 4C). To examine whether inhibition of $\gamma$-secretase affects multipotentiality, NPCs were immunostained using lineage-specific markers (Fig. $4 E$ ) and the number of lineage-specific cells was counted (Fig. 4D). NPCs treated with either DAPT or L-685,458 differentiated into all three lineages, suggesting that multipotentiality is not affected by $\gamma$-secretase activity (Fig. 4D,E). We further observed a slight increase in levels of all three lineages neurons, astrocytes and oligodendrocytes in NPCs treated with DAPT or L-685,458 compared with NPCs treated with vehicle (Fig. 4D). Together, these results suggest that lack of $\gamma$-secretase activity in NPCs induces a similar phenotype to that of downregulated PS1, implying that PS1 regulates NPCs differentiation in a $\gamma$-secretase-dependent manner.

\section{Downregulation of PS1 expression decreases extent of NPC proliferation and clone-formation capacity}

To examine whether enhanced NPC differentiation following PS1 downregulation was accompanied by reduced rate of proliferation, extent of $\mathrm{BrdU}$ intake was examined in neurospheres infected with lentiviral vectors expressing PS1 1.1 or PS1 4.11 siRNA or IR 8.1, IR 9.1 siRNA, or GFP-Lenti, using a proliferation assay. We observed that the number of cells incorporating BrdU was significantly lower in NPCs infected with siRNA for PS1 targeting than in NPCs infected with an IR siRNA (Fig. 5A). To examine whether reduction in NPC proliferation is the result of an effect of PS1 on NPC clone-formation capacity we quantified the number of NPCs giving rise to neurospheres following infection with lentiviral vectors. Hence, neurosphere cultures were infected with lentiviral vectors expressing PS1 1.1 or PS1 4.11 siRNA or IR 8.1, IR 9.1 siRNA, or GFP-Lenti. Infected cells were singly dissociated. The number of primary neurospheres formed was lower in NPCs infected with lentiviral vectors expressing PS1 siRNA compared with the number formed in NPCs infected with IR siRNA (Fig. 5B). To examine whether reduced proliferation is $\gamma$-secretase-dependent we repeated the BrdU uptake experiment using neurospheres treated with $\gamma$-secretase inhibitor. A significant reduction in BrdU uptake was observed in cells treated with the $\gamma$-secretase inhibitor L-685,458 (Fig. 5C; supplemental Fig. $2 B$, available at www.jneurosci.org as supplemental material) or DAPT (Fig. 5D; supplemental Fig. $2 A$, available at www.jneurosci.org as supplemental material).

\section{PS1 regulates NPC differentiation through $\beta$-catenin and EGFR signaling pathways}

To gain further insight into the mechanism by which PS1 exerts its effect on NPC proliferation, we examined expression level of neurogenic signals that are functionally associated with PS1, namely, notch-1, notch-1 ligands Del-1 and Jagged-1, $\beta$-catenin and EGFR as well as levels of the proliferation signal Tlx, the PS1 homolog PS2, and differentiation markers: PDGF, GFAP, $\beta$-III tubulin, and DCX (Fig. 6). Thus, neurosphere cultures were transduced with lentiviral vector expressing siRNA for PS1 targeting or IR siRNA and gene expression was analyzed by quantitative real-time RT-PCR. We observed a significant decrease in expression levels of $\beta$-catenin and EGFR, suggesting that these
A

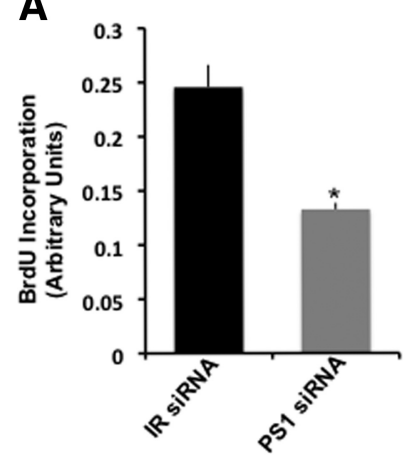

B

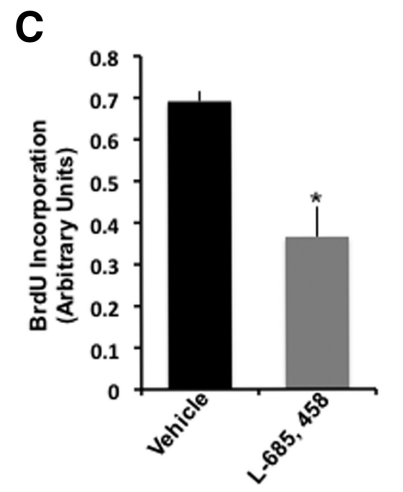

D
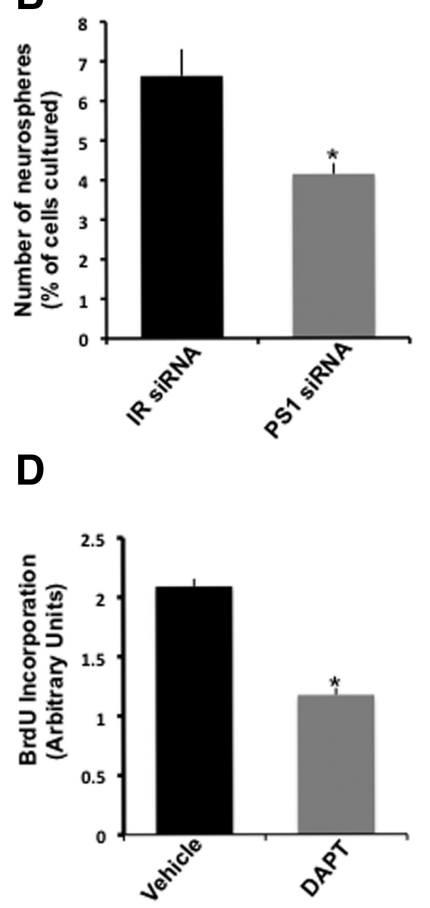

Figure 5. Reduced PS1 expression impairs proliferation and affects clone formation capacity. $\boldsymbol{A}$, Neurospheres infected with lentiviral vectors expressing siRNA for PS1 targeting exhibit reduced uptake of the thymidine analog BrdU compared with neurospheres infected with an irrelevant IR 8.1, 9.1 siRNA. B, A clonogenic assay shows that the number of clone forming cells in NPCs infected with lentiviral vectors expressing siRNA for PS1 targeting is significantly reduced compared with NPCs infected with an irrelevant IR 8.1, 9.1 siRNA. C, D, Neurospheres treated with L-685,458 (C) or DAPT (D) exhibit reduced uptake of BrdU compared with neurospheres treated with vehicle. $t$ test ${ }^{*} p<0.05$.

neurogenic signaling are downstream players in PS1 regulation of NPC differentiation. Expression of Tlx, Notch-1 and Jag-1 was slightly increased, while Del-1 was significantly increased. In addition, PS2 was significantly increased. PDGF expression levels were significantly higher in cultures with reduced PS1 expression, while $\beta$-III tubulin, DCX, and GFAP were slightly increased but were not significantly different, suggesting that the effect of PS1 on the latter three proteins is not regulated on the transcriptional level.

\section{Discussion}

Here we show that PS1 regulates NPC differentiation in the adult brain. Downregulation of PS1 expression reduces proliferation of NPCs, and enhances their differentiation without interfering with their multipotentiality. Our study suggests that PS1 may exert its effect through EGFR and $\beta$-catenin signaling, and that PS1 dominates major proliferation pathways in NPCs, namely, EGF and bFGF signaling. PS1 effect on NPC differentiation is $\gamma$-secretase dependent.

Lack of PS1 during embryonic development was suggested to impair neurogenesis through enhanced neuronal differentiation, without an effect on cell proliferation or apoptosis (Handler et al., 2000; Yang et al., 2000). Recent studies show that in PS1/PS2 conditional double knock-out mice, in which expression of both PSs are inactivated in NPC beginning at embryonic day 11 suggests that NPCs exit cell cycle and prematurely differentiate into neurons between E13.5 and E14.5 (Kim and Shen, 2008). Other studies examining the role of PS1 in stem cell maintenance during development suggest that PS1 plays a role in the development and/or maintenance of the anterior and intermediate lobes of the 


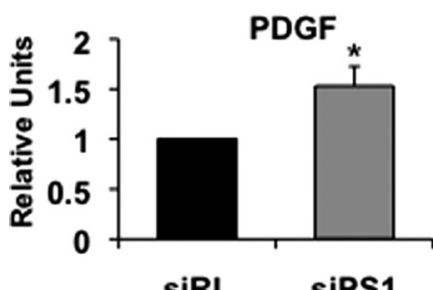

siRL

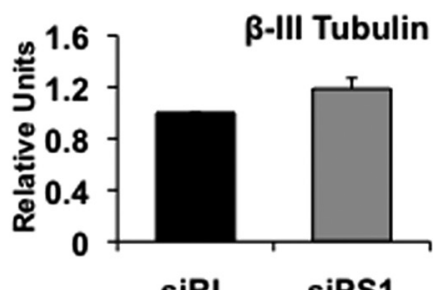

siRL

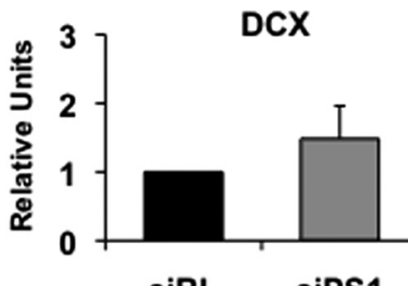

SiRL
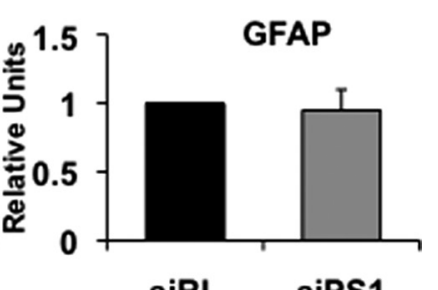
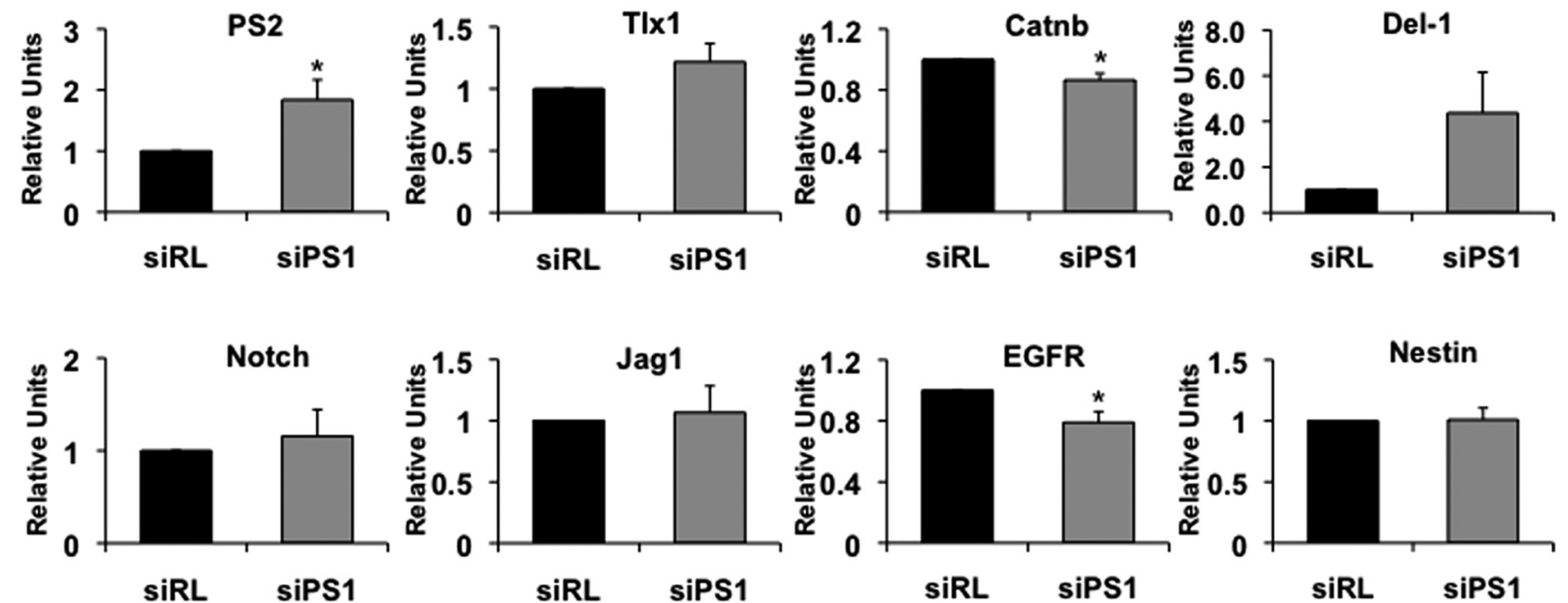

Figure 6. Gene expression in neurospheres after PS-1 knockdown. Neurosphere cultures were transduced with lentiviral vectors expressing PS1 shRNA for PS1 targeting or control IR shRNA and RNA was extracted for quantitative RT-PCR analysis of gene expression. Genes analyzed were EGFR, $\beta$-catenin (Catnb), presenilin-2 (PS2), PDGF, $\Delta$-1 (Del-1), $\beta$-III tubulin (bTub), DCX, Tlx1, Notch, Jagged-1 (Jag1), nestin, and GFAP. Values are mean \pm SEM of values relative to control $(n=6)$. Unpaired $t$ test, ${ }^{*} p<0.05$, and ANOVA, $p<0.05$, with $F>F_{\text {crit }}$.

pituitary gland (Nakajima et al., 2009). The present study determined that PS1 regulates neurogenesis postnatally as well. We show that downregulation of PS1 expression contracted the population of proliferating NPC in the SVZ and SGL, while enhancing the number of mature neurons and glia. This suggests that PS1 regulates a fundamental checkpoint that determines whether a cell would keep proliferating or differentiate.

Enhanced NPC differentiation observed following PS1 knockdown was similar to the effect exerted by treatment of NPCs with $\gamma$-secretase inhibitors. While the $\mathrm{IC}_{50}$ of L-685,458 and DAPT is $\sim 3-17 \mathrm{nM}$ and $100-170 \mathrm{nM}$, respectively (Shearman et al., 2000; Weihofen and Martoglio, 2003; Morohashi et al., 2006), both inhibitors enhanced NPC differentiation in the range of $0.5-20 \mu \mathrm{M} . \mathrm{IC}_{50}$ of these inhibitors was determined using in vitro cell-free assays with purified or enriched $\gamma$-secretase membrane prep and substrate. In addition, the readout of these experiments is the inhibition of $\mathrm{A} \beta$ production and the accumulation of amyloid precursor protein (APP)- $\mathrm{C}^{\prime}$-terminal fragments. In contrast, our experiments are based on whole-cell (primary culture) assays. APP is expressed at endogenous levels. The readout is a cellular phenotype that may involve the concerted action of several signaling pathways regulated by $\gamma$-secretase in addition to APP metabolites. In addition, the time course of our experiments is days (rather than hours). In support of that, previous studies examining the effect of these inhibitors on stem cell biology used doses similar to ours (Mori et al., 2006; Borghese et al., 2010).

We further show that downregulation of PS1 in neurosphere culture reduces the expression of two critical neurogenic signaling molecules, $\beta$-catenin and EGFR. PS1 is implicated in regulation of epidermal growth factor receptor EGFR and the Wnt/ $\beta$ catenin signaling, critical regulators of NSC self-renewal and pro- liferation (for review, see Shi et al., 2008). Substantial evidence exists for an interaction between PS1 and $\beta$-catenin and for the formation of a $\beta$-catenin/PS1 complex (Tesco et al., 1998; Tesco and Tanzi, 2000). $\beta$-Catenin is a critical downstream component of the canonical Wnt pathway, a central regulator of mammalian neural development and a regulator of NPCs in the SVZ, promoting proliferation of Mash1+ cells in the SVZ. Modulation of $\beta$-catenin signaling specifically in dividing cells in the adult mouse SVZ suggests $\beta$-catenin signaling is sufficient to increase the percentage of dividing Mash1 cells (Adachi et al., 2007). Wnt signaling plays a role in adult hippocampal neurogenesis as well, regulating proliferation of progenitor cells and neuronal differentiation (Lie et al., 2005). In the nucleus, stabilized $\beta$-catenin functions through TCF/LEF1 transcription factors and the notch-1/RBP-J complex, promoting proliferation of NPCs and suppressing their differentiation, respectively (Shimizu et al., 2008), possibly by activating the expression of target genes that are involved in the $G_{1}-S$ transition, such as cyclin D1 and c-Myc.

In addition, $\beta$-catenin and Notch intracellular domain (NICD) form a complex with the promoter region of the antineurogenic hes 1 gene, allowing its expression. Reduced expression of $\beta$-catenin following downregulation of PS1 in NPCs may suggest that less $\beta$-catenin reaches the nucleus, leading to attenuation of proliferation-inducing genes. In addition, our results show that expression level of the notch-1 ligand Del-1 is upregulated following PS1 knockdown. Notch1 is thought to be involved in the regulation of radial glia differentiation into committed NPCs during postnatal neurogenesis in the SGL, as well as during newborn neuron maturation (Breunig et al., 2007). Interestingly we observed an increase in PS2 and notch ligand expression, suggesting unsuccessful compensatory mechanisms 
to resume normal levels of PS and notch signaling, respectively. Shimizu et al. (2008) have shown that GSK3 $\beta$ inactivation and $\beta$-catenin stabilization in NPCs potentiated the promoter activity of hes 1 and hes 5 genes only when Notch signaling was activated. Further, stabilized $\beta$-catenin associates with N1IC and enhances its RBP-J-dependent transcription activity to induce hes 1 and hes 5 gene expression. Interestingly, in $h y h$ mutant mice reduced $\beta$-catenin correlates with early neurogenic differentiation (Chae et al., 2004). Conditional knock-out of $\beta$-catenin in the cortex and hippocampus resulted in reduced cell proliferation as a consequence of deficits in the neuroepithelium during development (Machon et al., 2003).

In summary, we show that PS1 plays a major role in adult neurogenesis, regulating NPC differentiation in a $\gamma$-secretasedependent manner. This study reveals a new molecular target for the manipulation of NPCs in the adult brain.

\section{References}

Adachi K, Mirzadeh Z, Sakaguchi M, Yamashita T, Nikolcheva T, Gotoh Y, Peltz G, Gong L, Kawase T, Alvarez-Buylla A, Okano H, Sawamoto K (2007) Beta-catenin signaling promotes proliferation of progenitor cells in the adult mouse subventricular zone. Stem Cells 25:2827-2836.

Aimone JB, Deng W, Gage FH (2010) Adult neurogenesis: integrating theories and separating functions. Trends Cogn Sci 14:325-337.

Borghese L, Dolezalova D, Opitz T, Haupt S, Leinhaas A, Steinfarz B, Koch P, Edenhofer F, Hampl A, Brüstle O (2010) Inhibition of notch signaling in human embryonic stem cell-derived neural stem cells delays $G_{1} / S$ phase transition and accelerates neuronal differentiation in vitro and in vivo. Stem Cells 28:955-964.

Breunig JJ, Silbereis J, Vaccarino FM, Sestan N, Rakic P (2007) Notch regulates cell fate and dendrite morphology of newborn neurons in the postnatal dentate gyrus. Proc Natl Acad Sci U S A 104:20558-20563.

Brummelkamp TR, Bernards R, Agami R (2002) A system for stable expression of short interfering RNAs in mammalian cells. Science 296:550-553.

Chae TH, Kim S, Marz KE, Hanson PI, Walsh CA (2004) The hyh mutation uncovers roles for alpha Snap in apical protein localization and control of neural cell fate. Nat Genet 36:264-270.

Chevallier NL, Soriano S, Kang DE, Masliah E, Hu G, Koo EH (2005) Perturbed neurogenesis in the adult hippocampus associated with presenilin-1 A246E mutation. Am J Pathol 167:151-159.

Choi SH, Veeraraghavalu K, Lazarov O, Marler S, Ransohoff RM, Ramirez JM, Sisodia SS (2008) Non-cell-autonomous effects of presenilin 1 variants on enrichment-mediated hippocampal progenitor cell proliferation and differentiation. Neuron 59:568-580.

Demars M, Hu YS, Gadadhar A, Lazarov O (2010) Impaired neurogenesis is an early event in the etiology of familial Alzheimer's disease in transgenic mice. J Neurosci Res 88:2103-2117.

De Strooper B, Saftig P, Craessaerts K, Vanderstichele H, Guhde G, Annaert W, Von Figura K, Van Leuven F (1998) Deficiency of presenilin-1 inhibits the normal cleavage of amyloid precursor protein. Nature 391:387-390.

De Strooper B, Annaert W, Cupers P, Saftig P, Craessaerts K, Mumm JS, Schroeter EH, Schrijvers V, Wolfe MS, Ray WJ, Goate A, Kopan R (1999) A presenilin-1-dependent gamma-secretase-like protease mediates release of Notch intracellular domain [see comments]. Nature 398:518-522.

Feng R, Rampon C, Tang YP, Shrom D, Jin J, Kyin M, Sopher B, Miller MW, Ware CB, Martin GM, Kim SH, Langdon RB, Sisodia SS, Tsien JZ (2001) Deficient neurogenesis in forebrain-specific presenilin-1 knockout mice is associated with reduced clearance of hippocampal memory traces. Neuron 32:911-926.

Handler M, Yang X, Shen J (2000) Presenilin-1 regulates neuronal differentiation during neurogenesis. Development 127:2593-2606.

Herreman A, Serneels L, Annaert W, Collen D, Schoonjans L, De Strooper B (2000) Total inactivation of gamma-secretase activity in presenilindeficient embryonic stem cells. Nat Cell Biol 2:461-462.

Kim WY, Shen J (2008) Presenilins are required for maintenance of neural stem cells in the developing brain. Mol Neurodegener 3:2.

Kriegstein A, Alvarez-Buylla A (2009) The glial nature of embryonic and adult neural stem cells. Annu Rev Neurosci 32:149-184.

Lazarov O, Marr RA (2010) Neurogenesis and Alzheimer's disease: At the crossroads Exp Neurol 223:267-281.

Li YM, Xu M, Lai MT, Huang Q, Castro JL, DiMuzio-Mower J, Harrison T,
Lellis C, Nadin A, Neduvelil JG, Register RB, Sardana MK, Shearman MS, Smith AL, Shi XP, Yin KC, Shafer JA, Gardell SJ (2000) Photoactivated gamma-secretase inhibitors directed to the active site covalently label presenilin 1. Nature 405:689-694.

Lie DC, Colamarino SA, Song HJ, Désiré L, Mira H, Consiglio A, Lein ES, Jessberger S, Lansford H, Dearie AR, Gage FH (2005) Wnt signalling regulates adult hippocampal neurogenesis. Nature 437:1370-1375.

Machon O, van den Bout CJ, Backman M, Kemler R, Krauss S (2003) Role of beta-catenin in the developing cortical and hippocampal neuroepithelium. Neuroscience 122:129-143.

Mori H, Ninomiya K, Kino-oka M, Shofuda T, Islam MO, Yamasaki M, Okano H, Taya M, Kanemura Y (2006) Effect of neurosphere size on the growth rate of human neural stem/progenitor cells. J Neurosci Res 84:1682-1691.

Morohashi Y, Kan T, Tominari Y, Fuwa H, Okamura Y, Watanabe N, Sato C, Natsugari H, Fukuyama T, Iwatsubo T, Tomita T (2006) C-terminal fragment of presenilin is the molecular target of a dipeptidic gammasecretase-specific inhibitor DAPT ( $\mathrm{N}$-[N-(3,5-difluorophenacetyl)-Lalanyl]-S-phenylglycine $t$-butyl ester). J Biol Chem 281:14670-14676.

Nakajima M, Watanabe S, Okuyama S, Shen J, Furukawa Y (2009) Restricted growth and insulin-like growth factor-1 deficiency in mice lacking presenilin-1 in the neural crest cell lineage. Int J Dev Neurosci 27:837-843.

Paxinos G, Franklin KJB (2004) The mouse brain in stereotaxic coordinates. San Diego: Academic.

Selkoe DJ (2001) Alzheimer's disease: genes, proteins, and therapy. Physiol Rev 81:741-766.

Shearman MS, Beher D, Clarke EE, Lewis HD, Harrison T, Hunt P, Nadin A, Smith AL, Stevenson G, Castro JL (2000) L-685,458, an aspartyl protease transition state mimic, is a potent inhibitor of amyloid beta-protein precursor gamma-secretase activity. Biochemistry 39:8698-8704.

Shen J, Bronson RT, Chen DF, Xia W, Selkoe DJ, Tonegawa S (1997) Skeletal and CNS defects in Presenilin-1-deficient mice. Cell 89:629-639.

Shi Y, Sun G, Zhao C, Stewart R (2008) Neural stem cell self-renewal. Crit Rev Oncol Hematol 65:43-53.

Shimizu T, Kagawa T, Inoue T, Nonaka A, Takada S, Aburatani H, Taga T (2008) Stabilized beta-catenin functions through TCF/LEF proteins and the Notch/RBP-Jkappa complex to promote proliferation and suppress differentiation of neural precursor cells. Mol Cell Biol 28:7427-7441.

Suh H, Deng W, Gage FH (2009) Signaling in adult neurogenesis. Annu Rev Cell Dev Biol 25:253-275.

Tesco G, Tanzi RE (2000) GSK3 beta forms a tetrameric complex with endogenous PS1-CTF/NTF and beta-catenin. Effects of the D257/D385A and FAD-linked mutations. Ann N Y Acad Sci 920:227-232.

Tesco G, Kim TW, Diehlmann A, Beyreuther K, Tanzi RE (1998) Abrogation of the presenilin 1/beta-catenin interaction and preservation of the heterodimeric presenilin 1 complex following caspase activation. J Biol Chem 273:33909-33914.

Tiscornia G, Singer O, Verma IM (2006a) Design and cloning of lentiviral vectors expressing small interfering RNAs. Nat Protoc 1:234-240.

Tiscornia G, Singer O, Verma IM (2006b) Production and purification of lentiviral vectors. Nat Protoc 1:241-245.

Wang R, Dineley KT, Sweatt JD, Zheng H (2004) Presenilin 1 familial Alzheimer's disease mutation leads to defective associative learning and impaired adult neurogenesis. Neuroscience 126:305-312.

Weihofen A, Martoglio B (2003) Intramembrane-cleaving proteases: controlled liberation of proteins and bioactive peptides. Trends Cell Biol 13:71-78.

Wen PH, Hof PR, Chen X, Gluck K, Austin G, Younkin SG, Younkin LH, DeGasperi R, Gama Sosa MA, Robakis NK, Haroutunian V, Elder GA (2004) The presenilin-1 familial Alzheimer disease mutant P117L impairs neurogenesis in the hippocampus of adult mice. Exp Neurol 188:224-237.

Wines-Samuelson M, Shen J (2005) Presenilins in the developing, adult, and aging cerebral cortex. Neuroscientist 11:441-451.

Wolfe MS, Xia W, Ostaszewski BL, Diehl TS, Kimberly WT, Selkoe DJ (1999) Two transmembrane aspartates in presenilin-1 required for presenilin endoproteolysis and gamma-secretase activity. Nature 398:513-517.

Xie Z, Romano DM, Kovacs DM, Tanzi RE (2004) Effects of RNA interferencemediated silencing of gamma-secretase complex components on cell sensitivity to caspase-3 activation. J Biol Chem 279:34130-34137.

Yang X, Handler M, Shen J (2000) Role of presenilin-1 in murine neural development. Ann N Y Acad Sci 920:165-170.

Zhang Z, Nadeau P, Song W, Donoviel D, Yuan M, Bernstein A, Yankner BA (2000) Presenilins are required for gamma-secretase cleavage of betaAPP and transmembrane cleavage of Notch-1. Nat Cell Biol 2:463-465. 